\title{
The Measured Effect Magnitude of Co-Morbidities on Burn injury Mortality
}

Laquanda Knowlin, M.D, Lindsay Stanford, B.S, Danier Moore, M.D, Bruce Cairns, M.D, and Anthony Charles, M.D, MPH

Department of Surgery, University of North Carolina, North Carolina Jaycee Burn center

\section{Abstract}

Introduction-The ability to better prognosticate burn injury outcome is challenging and historically, most center use the Baux or revised Baux score to help prognosticate burn outcome, however, the weighted contribution of comorbidity on burn mortality has traditionally not been accounted for nor adequately studied. We therefore sought to determine the effect of comorbidities, using the Charlson comorbidity index (CCI) on burn mortality.

Methods-The purpose of this study was to determine the effect of comorbidities on burn injury mortality as determined by the LA50 (lethal TBSA burn at which $50 \%$ of the cohort will succumb from the burn injury) in a retrospective analysis of patients admitted to a regional burn center from 2002-2012. Independent variables analyzed included basic demographics, burn mechanism, presence of inhalation injury, TBSA (total body surface area), length of hospital stay, and preexisting comorbidities. Bivariate analysis was performed and logistic regression modeling using significant variables was utilized to estimate odds of death.

Results-7640 patients were included in this study. Overall survival rate was $96 \% .40 \%$ of our burn cohort had at least one comorbidity. There was a linear increase in the likelihood of death with an increase in CCI. The logistic regression model for mortality outcomes identified four statistically significant variables: age, TBSA, inhalational injury and the presence of comorbidities $(\mathrm{OR}=1.59$ for each 1 point increase in CCI; 95\% CI 1.44-1.77). The unadjusted LA50 was 53\% for the entire cohort. Partial adjustment multivariate regression controlling for burn mechanism and inhalation injury only, produced a slight reduction in LA50 for the 0-18 and 19-64 age categories to $76 \%$ and $48 \%$, respectively, but a significant decrease occurred in the $\geq 65$ years age group with a reduced LA50 to $20 \%$ ( $\mathrm{p}<0.001$ ). After full adjustment for all significant covariates, including comorbidities, the independent magnitude of effect of comorbidities on the LA50 was evident in the $<65$ cohort. The full adjustment showed a LA50 decreased by 15 and $5 \%$, respectively in the $0-18$ and $>18-65$ age groups respectively $(\mathrm{p}<0.001)$, however, in the $>65$ years age cohort there was no change in the LA50.

Conclusion-Preexisting comorbidities have a significant effect on burn injury mortality in all age groups, particularly the younger burn population. The measured effect of comorbidities in the $>65 y r$ age cohort was mitigated by the co-linearity between age and comorbidities. The inclusion

Anthony Charles MD, MPH, FACS, Associate Professor of Surgery, UNC School of Medicine, University of North Carolina, 4008 Burnett Womack Building, CB 7228, Tel: 919-966-4389, Fax: 919-9660369, anthchar@med.unc.edu. 
of CCI is imperative so as to better prognosticate burn outcome and help guide expectations and resource utilization, particularly in the younger burn cohort..

\section{Introduction}

Burn injuries are among the most devastating of all injuries and a major global public health crisis.[1,2] Burns are the fourth most common type of trauma worldwide, following traffic accidents, falls, and interpersonal violence.[3] Survival following burn injury has increased in the United States over the past 50 years. This can be attributed the advances in our understanding of burn injury, early nutrition, improved critical care, infection control and early excision and grafting of burn wounds within a multidisciplinary burn care team model.

Objective estimates of the probability of death from burn injuries are difficult. The most widely used formulas for the prediction of mortality from burns are based on a minimal set of easily obtained variables. A classic example based on the Baux Score[4,5] calculated the percent likelihood of mortality as the patient's age in years plus the percentage of the total body-surface area (TBSA) that was burned. This formula has become obsolete.[6] The ability to better prognosticate burn outcome is challenging and most burn centers use the Baux score or its revision (probability of mortality $=$ Age + Percent TBSA + Presence of Inhalation Injury), to help prognosticate of burn injury outcome upon presentation, but the weighted contribution of comorbidity on burn mortality has not been adequately studied.

In 1987, Charlson et al. developed the Charlson comorbidity Index (CCI) to predict the tenyear mortality of patients with a range of medical conditions.[7] Each condition is given a score from one to six. A higher score predicted the increased likelihood of mortality. Older adults also tend to be at increased risk for other adverse outcomes including longer lengths of stay and higher hospital costs following burn injury as compared with younger patients with similar injuries.[8] There are several potential reasons for worse burn outcome in older adults. Preexisting medical problems_-including cardiovascular, pulmonary, and renal disease-can complicate fluid resuscitation, a cornerstone of the early post-burn management period. Surgical management can also be more complicated in older patients because blood loss, intubation, and anesthesia may be poorly tolerated.[9] However, the relative impact of pre-existing medical comorbidities on survival following burn injury remains poorly understood.

Given the increasing number of older adults in the population and their persistent injury risk factors, there will likely be a greater number of older adults sustaining burn injury. We therefore sought to examine the impact of pre-existing medical co-morbidities on in-hospital mortality. The primary objective of the study was to determine the measured effect comorbidities, using the updated Charlson comorbidity index, on burn injury mortality based on LA50 (lethal TBSA burn at which 50\% of the cohort will succumb from the burn injury). We hypothesize that preexisting comorbidities will have a significantly measureable effect on burn injury mortality. 


\section{Methods}

This is a retrospective study of all burn patients admitted to the University of North Carolina Jaycee Burn Center from 2001 to 2012. This study was conducted following approval from our Institutional Review Board. The North Carolina Jaycee Burn Center at UNC was established in 1981 and averages more than 1200 acute admissions per year. The burn center is a single unit, 36-bed facility that has been verified by the American Burn Association for pediatric and adult care.

The medical records of subjects identified by the UNC Burn database query were reviewed to verify baseline demographic data, injury characteristics, and provide detailed information on medical comorbidities. Injury characteristics of interest included burn etiology, TBSA burned, presence of inhalation injury, and intubation status on admission to the burn center. Inhalation injury diagnosis was based on history, physical examination, and/or bronchoscopic examination.

To examine the effect of baseline medical comorbidities on outcome, a modified Charlson Comorbidity Index score was calculated for each patient. The standardized Charlson Index has been reported to accurately predict the probability of mortality within 1 year for a number of medical conditions. [7,10] The score is the weighted sum of comorbid conditions. There are 17 comorbid conditions included in the score and each is assigned a weight from 1 to 6 points. The weighted sum of all comorbid conditions is the patient's Charlson score. (Table 1)

The outcomes of interest in this study included in-hospital mortality. Baseline patient and injury characteristics were compared between groups (Lived/Died) using Analysis of Variance for continuous variables and chi-squared for discrete variables. We employed both univariate and multivariate models in order to determine the relative influence of comorbidities when controlling for other variables. To determine LA 50 TBSA, we used a multivariate logistic regression model controlling for pertinent confounders (age, inhalation injury, mechanism of injury and comorbidities). We categorized our burn cohort into 3 age groups (0-18, 19-64, and 265$)$ and determined the LA50 for each patient population. We used linear regression to examine hospital length of stay and logistic regression to examine mortality. A comparison of Area Under the Receiver Operating Characteristic (AUROC) curve between regression models was done with and without CCI to determine accuracy of including CCI in predicting burn mortality. Assessment of co-linearity between variables in the logistic regression model was performed using the Variance Inflation Factor (VIF) Stata/MP (Version 12) (Statacorp, College Station, TX) was used for all data management and statistical analysis.

\section{Results}

A total of 7,640 patients were admitted and treated during the study period with a mean age of $32 \pm 22$ years. Of these patients, $68 \%$ were males. The age category cohort of $0-18,19-$ 64 , and $\ 65$ years accounted for $30 \%, 62 \%$ and $8 \%$, respectively. Caucasians made up 51\% of the population. The most common mechanism of burn injury was scald (49\%) followed 
by flame injury (45\%). The overall mean TBSA for this population was $8.6 \pm 12 \%$. (Table 2) There was no significant difference in TBSA based on race or sex but a difference in noted within the age categories. The mean \%TBSA for each age the category cohort of $0-18,19-$ 64 , and $\succeq 65$ years was $6.8 \pm 7.7 \%, 9 \pm 13.1 \%$, and $11.6 \pm 15.3 \%$, respectively $(p<0.001)$. The mean length of hospital and ICU stay was $12.7 \pm 24.7$ days and $5.1 \pm 20.2$ days respectively $(p<0.001)$. Burn patients with at least one comorbidity represented $40 \%$ of the population $(\mathrm{n}=3,057)$.

During the study period, the overall mortality was $4 \%$. The mean age of survivors vs. nonsurvivors was $31 \pm 21.9$ years and $58 \pm 20.5$ years, respectively. (Table 3 ) TBSA was significantly associated with mortality $(\mathrm{p}<0.001)$. The average TBSA for patients who died was $39.9 \pm 29.2 \%$. Although patients with an inhalation injury represented a small portion (7\%) of the cohort, $23 \%$ of these patients in the burn cohort died. Patients who died presented to the hospital with an average of $2.6 \pm 1.9$ comorbidities. Flame burns were associated with significantly higher mortality rate (7\%) than scald (1\%) and other types of burns $(4 \%, \mathrm{p}<0.001)$. Race and gender had no significant impact on mortality.

A multivariate logistic regression was then performed on patient demographics and clinical characteristics in a model for mortality outcomes identifying five variables as statistically significant: age, TBSA, mechanism of injury, presence of inhalation injury (odds ratio [OR] $=2.85 ; 95 \%$ confidence interval $[\mathrm{CI}] 1.99-4.08$ ), and presence of comorbidities. (Table 4) The patient groups older than 18 years of age, 19 to $64(\mathrm{OR}=2.92 ; 95 \% \mathrm{CI} 1.31-6.52)$ and older than 65 years old ( $\mathrm{OR}=8.32 ; 95 \%$ CI 3.347-20.793), had higher odds of mortality compared to their younger counterparts. The odds of mortality increased 1.59 times $(95 \%$ confidence interval 1.44-1.77) for each point increase in CCI after controlling for patient demographics and burn characteristics. There is a linear increase in the likelihood of death with an increase in CCI. (Figure 1) Comparison of AUROC was done on logistic regression models with and without CCI to determine accuracy of this variable in predicting mortality. There was a significant difference between the two models $(\mathrm{p}<0.01)$.

LA50 determination was based on a logistic regression of burn outcome by TBSA that increased by a geometric progression. (Table 5) The unadjusted LA50 for the entire study population was $53 \%$. A partial adjustment for inhalation injury and mechanism of burn led to a reduction in LA50 of $8 \%$. (Figures $2 \mathrm{~A} \& \mathrm{~B}$ ). A multivariate logistic regression was then repeated using significant variables from the bivariate analysis, adjusting for age, mechanism of burn, presence of inhalation injury, and comorbidities. The unadjusted regression model for each age group showed a LA50 for age groups 0-18, 19-64, and 65 years of $81 \%, 55 \%$, and $30 \%$ TBSA, respectively. As expected, there was a decrease in LA50 for TBSA as mechanism of burn and inhalation injury were factored into the model. Partial adjustment multivariate regression controlling for burn mechanism and inhalation injury only, produced a slight reduction in LA50 for the 0-18 and 19-64 age categories to $76 \%$ and $48 \%$, respectively (Fig. 3A \&4A), but a significant decrease occurred in the $\geq 65$ years age group with a reduced LA50 to 20\% (p<0.001).(Fig 5A) After full adjustment for all significant covariates, including comorbidities, the independent magnitude of effect of comorbidities on the LA50 was evident in the $<65$ cohort. When compared to the partially adjusted model, the full adjustment showed LA50 decreased further from 76 to $61 \%$ and 48 
to $43 \%$ TBSA, respectively in the $0-18$ and $>18-65$ age groups respectively $(\mathrm{p}<0.001)$, however in the $>65$ years age group, there was no change in the LA50. (Fig 5B) These results suggest that the presence of documented pre-existing comorbidities has a significant effect on the predicted probability of mortality, particularly in burn patients $\leq 65$ years. Investigation of co-linearity in the logistic regression model was performed using Variance Inflation Factor. Independent variables TBSA, Inhalation injury and mechanism of burn had VIF less than 4. Age and comorbidities each had a VIF of 21 and 146 respectively. An interaction term for produced a VIF of 193 and tolerance of 0.005

\section{Discussion}

In this study, we show the weighted contribution of the addition of comorbidities, using the $\mathrm{CCI}$ to the predictive probability of death following burn injury. Previous studies examining mortality from burns have identified three major risk factors associated with increased mortality: age $>60$ years old, TBSA $>40 \%$, and presence of inhalation injury.[11-13] Presence of all three risk factors is associated with mortality of 90\%. [11,12] Smoke inhalation injury is generally considered to be the strongest predictor of burn mortality. [13] In our burn population, however, we found that the presence of preexisting medical comorbidities had significant impact on mortality as evident by significant reduction in LA50 in those aged $\leq 65$ years. In addition, we found the measured effect of comorbidities to be most pronounced in patients $\leq 18$, suggesting that younger patients with medical comorbidities are more susceptible to worse outcomes. In the $\geq 65$ age group the fully adjusted model showed only a $1 \%$ TBSA decrease in LA50 from the partially adjusted model due to co-linearity between age and the presence of comorbidities. Co-linearity was confirmed with VIF greater than 10 and tolerance close to 0 .

Outcomes in trauma patients have been known to be effected by fraility. ${ }^{* * *}$ Frailty has been defined in older adults as the increase vulnerability to stressors due to age-related physiologic declines across multiple organ systems and risk of adverse outcomes.** However, frailty isn't related to just aging alone and can affect those that are chronically ill at younger ages.** There is no current gold standard for diagnosing frailty. There are many screening tools such as FRAIL (Fatigue, Resistance, Ambulation, Illness, Loss of Weight) and Frailty Index (FI), that can be utilized for early assessment and identification of vulnerable patients. ${ }^{* * *}$ Once assessment has been completed, physicians and family must weigh the risk and benefits of interventions as well as make decisions regarding aggressiveness of care.

Historically, several models have been created to help guide prognostication of burn outcome. The Baux score described in 1961 was used to predict mortality based on age and percent TBSA alone. [4]This model did not account for inhalation injury. The Abbreviated Burn Severity Index (ABSI) created in 1982 subsequently accounted for the presence of inhalation injury but excluded comorbidities. [14]Since 2007, other prediction models that have been utilized are the Belgian Outcome in Burn Injury (BOBI) model and revised Baux score to predict burn outcomes. However, these latest models do not take into account the effects preexisting medical conditions[15,16] and may result in overestimation or underestimation of burn severity. 
There are a few studies that examined the impact of comorbidities on burn injuries.

However, those studies were done on a smaller population and didn't adequately weigh the contribution of comorbidities on burn mortality. [17-22] A larger 2007 study was done by Thombs et al [23] looked at the effect of various comorbidities on burn injury mortality based on the National Burn Repository (NBR) report on 31,338 burn records from 19952005. They found that various pre-existing medical conditions, using the Charlson Comorbidity index and Elixhauser method of comorbidity measurement, affected burn mortality. Medical conditions such as HIV/Aids, metastatic cancer, liver disease, and renal disease had a poor prognostic outcome in acute burn injury.

The limitations of this study are those inherent to any study with a retrospective. Though we have a great sample size, this is a single center study, which may affect generalizability of our findings. Utilizing a large administrative dataset with pertinent comorbidity data would help overcome this limitation or indeed a prospective multicenter study. Also, the contribution of frailty and its effect on to outcome was not evaluated. Furthermore, the Charlson comorbidity index was originally based on the predictive power to estimate mortality in medicine patients and was never intended to generalizations to surgical or burn cohort. It has undergone several modifications and has been utilized and validated in other surgical patient cohort.[23-29]

\section{Conclusion}

Patient mortality remains the primary outcome measure for burn care. Scoring systems aim to use the most predictive premorbid and injury factors to yield an expected likelihood of death for a given patient. Age, burn surface area and inhalational injury remain the mainstays of burn prognostication, but their fidelity is imprecise without accounting for preexisting comorbidity data. Our study has elucidated the measured effect of comorbidities on the LA 50 TBSA. With increasing health care cost, the inclusion of CCI is imperative to better prognosticate burn outcome and help guide expectations and resource utilization.

\section{References}

1. Forjuoh SN. Burns in low- and middle-income countries: a review of available literature on descriptive epidemiology, risk factors, treatment, and prevention. Burns. 2006; 32:529-537. [PubMed: 16777340]

2. Peck MD, Kruger GE, van der Merwe AE, et al. Burns and fires from non-electric domestic appliances in low and middle income countries Part I. The scope of the problem Burns. 2008; 34:303. [PubMed: 18206314]

3. Mathers, C., Boerma, T., Fat, DM. The Global Burden of Disease: 2004 Update. World Health Organization; Geneva: 2008.

4. Baux, S. Contribution a l'Etude du traitement local des brulures thermigues etendues. Paris: These; 1961.

5. Zawacki BE, Azen SP, Imbus SH, Chang YT. Multifactorial probit analysis of mortality in burned patients. Ann Surg. 1979; 189:1-5. [PubMed: 758852]

6. Ryan CM, Schoenfeld DA, Thorpe WP, Sheridan RL, Cassem EH, Tompkins RG. Objective estimates of the probability of death from burn injuries. N Engl J Med. 1998 Feb 5; 338(6):362-6. [PubMed: 9449729] 
7. Charlson ME, Pompei P, Ales KL, et al. A new method of classifying prognostic comorbidity in longitudinal studies: development and validation. J Chronic Dis. 1987; 40:373-383. [PubMed: 3558716]

8. Li BG, Hsu WS, Shih TS. Causes of death in aged burn patients: analysis of 36 cases. Burns. 1990; 16:207-10. [PubMed: 2383362]

9. Wibbenmeyer LA, Amelon MJ, Morgan LJ, Robinson BK, Chang PX, Lewis R 2nd, et al. Predicting survival in an elderly burn patient population. Burns. 2001; 27:583-90. [PubMed: 11525852]

10. Needham DM, Scales DC, Laupacis A, Pronovost PJ. A systematic review of the Charlson Comorbidity Index using Canadian administrative databases: a perspective on risk adjustment in critical care research. J Crit Care. 2005; 20:12-9. [PubMed: 16015512]

11. Brusselaiers N, Hoste EAJ, Monstrey S, Colpaert KE, De Waele JJ, Vandewoude KH, Blot SI. Outcome and changes over time in survival following severe burns from 1985 to 2004. Intensive Care Med. 2005; 31:1648-53. [PubMed: 16220315]

12. Ryan C, Schoenfeld DA, Thorpe WP, Sheridan RL, Cassem EH, Tompkins RG. Objective estimates of the probability of death from burn injuries. NEJM. 1998; 338:362-6. [PubMed: 9449729]

13. Meshulam-Derazon S, Nachumovsky S, Ad-El D, Sulkes J, Hauben DJ. Prediction of morbidity and mortality on admission to a burn unit. Plast Reconstr Surg. 2006; 118(1):116-20. [PubMed: 16816682]

14. Tobiasen J, Hiebert JM, Edlich RF. The abbreviated burn severity index. Ann Emerg Med. 1982; 11(5):260-262. [PubMed: 7073049]

15. Belgian Outcome in Burn Injury Study Group. Development and validation of a model for prediction of mortality in patients with acute burn injury. Br J Surg. 2009; 96(1):111-117. [PubMed: 19109825]

16. Osler T, Glance LG, Hosmer DW. Simplified estimates of the probability of death after burn injuries: extending and updating the Baux score. J Trauma. 2010; 68(3):690-697. [PubMed: 20038856]

17. Germann G, Barthold U, Lefering R, Raff T, Hartmann B. The impact of risk factors and preexisting conditions on the mortality of burn patients and the precision of predictive admissionscoring systems. Burns. 1997; 23(3):195-203. [PubMed: 9232278]

18. Germann G, Barthold U, Lefering R, Raff T, Hartmann B. The impact of risk factors and preexisting conditions on the mortality of burn patients and the precision of predictive admissionscoring systems. Burns. 1997; 23(3):195-203. [PubMed: 9232278]

19. Covington DS, Wainwright DJ, Parks DH. Prognostic indicators in the elderly patient with burns. J Burn Care Rehabil. 1996; 17:222-30. [PubMed: 8736367]

20. Barret JP, Gomez P, Solano I, Gonzalez-Dorrego M, Crisol FJ. Epidemiology and mortality of adult burns in Catalonia. Burns. 1999; 25:325-9. [PubMed: 10431980]

21. Horbrand F, Schrank C, Henckel-Donnersmarck G, Mühlbauer W. Integration of preexisting diseases and risk factors in the Abbreviated Burn Severity Index (ABSI). Anasthesiol Intensivmed Notfallmed Schmerzther. 2003; 38:151-7. [PubMed: 12635040]

22. Raff T, Germann G, Barthold U. Factors influencing the early prediction of outcome from burns. Acta Chir Plast. 1996; 38:122-7. [PubMed: 9037788]

23. Thombs BD, Singh VA, Halonen J, Diallo A, Miner SM. The Effects of Preexisting Medical Comorbidities on Mortality and Length of Hospital Stay in Acute Burn Injury: Evidence From a National Sample of 31,338 Adult Patients. Ann Surg. 2007; 245(4):629-634. PMC. Web. 28 Sept. 2015. [PubMed: 17414613]

24. Lundgren RS, Kramer CB, Rivara FP, Wang J, Heimbach DM, Gibran NS, Klein MB. Influence of comorbidities and age on outcome following burn injury in older adults. J Burn Care Res. 2009; 30(2):307-314. [PubMed: 19165104]

25. Deyo RA, Cherkin DC, Ciol MA. Adapting a clinical comorbidity index for use with ICD-9-CM administrative databases. Journal of Clinical Epidemiology. 1992; 45(6):613-619. [PubMed: 1607900] 
26. Romano PS, Roos LL, Jollis JG. Adapting a clinical comorbidity index for use with ICD-9-CM administrative data: differing perspectives. J Clin Epidemiol. 1993; 46(10):1075-1079. [PubMed: 8410092]

27. Halfon P, Eggli Y, van Melle G, Chevalier J, Wasserfallen JB, Burnand B. Measuring potentially avoidable hospital readmissions. J Clin Epidemiol. 2002; 55(6):573-587. [PubMed: 12063099]

28. Schneeweiss S, Wang PS, Avorn J, Glynn RJ. Improved comorbidity adjustment for predicting mortality in Medicare populations. Health Serv Res. 2003; 38(4):1103-1120. [PubMed: 12968819]

29. Quan H, Sundararajan V, Halfon P, Fong A, Burnand B, Luthi JC, Saunders LD, Beck CA, Feasby TE, Ghali WA. Coding algorithms for defining comorbidities in ICD-9-CM and ICD-10 administrative data. Med Care. 2005; 43(11):1130-1139. [PubMed: 16224307] 


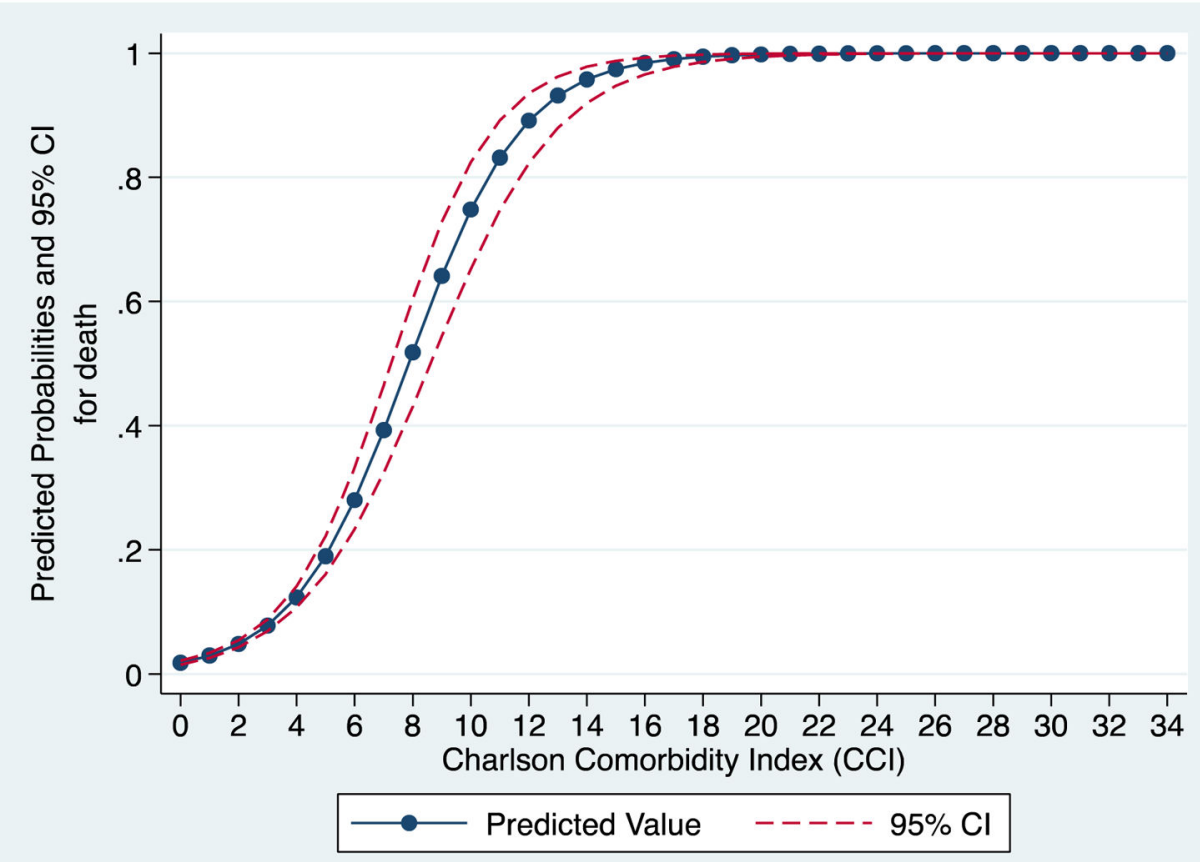

Figure 1.

The predicted probability for death based on Charlson co-morbidity index 
A
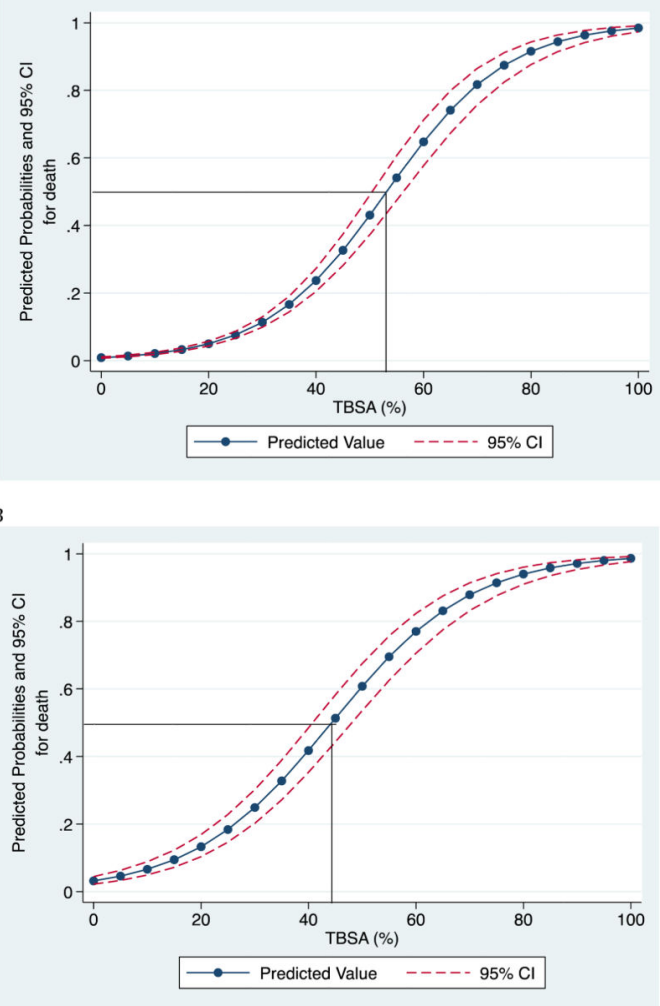

Figure 2.

Unadjusted (A) and Adjusted (B) LA50 \% TBSA for entire burn cohort

* Adjusted for Burn Mechanism, Age and Inhalational injury 


\section{Table 1}

\section{Charlson Comorbidity Index score System}

\begin{tabular}{lc}
\hline Comorbidity & Score \\
\hline Myocardial infarction & 1 \\
Congestive heart failure & 1 \\
Peripheral vascular disease & 1 \\
Cerebrovascular disease & 1 \\
Dementia & 1 \\
Chronic pulmonary disease & 1 \\
Rheumatologic disease & 1 \\
Peptic ulcer disease & 1 \\
Mild liver disease & 1 \\
Diabetes without chronic complications & 1 \\
\hline Diabetes with chronic complications & 2 \\
Hemiplegia or paraplegia & 2 \\
Renal disease & 37 \\
Solid tumor & 2 \\
Leukema & 2 \\
Lymphoma & 2 \\
\hline Moderate or severe liver disease & 2 \\
\hline AIDS/HIV & 6 \\
\hline Metastatic solid tumor & 1 \\
\hline Maximum comorbidity score & 1 \\
\hline
\end{tabular}

Burns. Author manuscript; available in PMC 2017 January 30. 


\section{Table 2}

Patient characteristics.

\begin{tabular}{|c|c|c|}
\hline Patient characteristics $(n=7,640)$ & $n$ & Mean $( \pm$ SD) or $\%$ \\
\hline \multicolumn{3}{|l|}{ Sex } \\
\hline Male & 5,244 & $69 \%$ \\
\hline Female & 2,396 & $31 \%$ \\
\hline \multicolumn{3}{|l|}{ Age } \\
\hline Overall & & $32.0( \pm 22.4)$ \\
\hline 0-18 years & 2,298 & $30 \%$ \\
\hline 19-64 years & 4,744 & $62 \%$ \\
\hline$\geq 65$ years & 598 & $8 \%$ \\
\hline \multicolumn{3}{|l|}{ Type of Burn } \\
\hline Flame & 3,426 & $45 \%$ \\
\hline Scald & 3,678 & $49 \%$ \\
\hline Other & 480 & $6 \%$ \\
\hline \multicolumn{3}{|l|}{ Inhalation } \\
\hline Inhalation injury & 562 & $7 \%$ \\
\hline No inhalation injury & 7,078 & $93 \%$ \\
\hline \multicolumn{3}{|l|}{ Charlson Comorbidity Index (CCI) } \\
\hline \multirow[t]{2}{*}{ Overall mean } & 7,640 & $0.906864( \pm 1.4)$ \\
\hline & & $40 \%$ \\
\hline \multicolumn{3}{|l|}{ TBSA } \\
\hline Overall mean & 7,640 & $8.6( \pm 12.0)$ \\
\hline \multicolumn{3}{|l|}{ By sex } \\
\hline Male & 5,244 & $9.0( \pm 12.6)$ \\
\hline Female & 2,396 & $7.7( \pm 10.7)$ \\
\hline \multicolumn{3}{|l|}{ By age } \\
\hline 0-18 years & 2,298 & $6.8( \pm 7.7)$ \\
\hline 19-64 years & 4,744 & $9.0( \pm 13.1)$ \\
\hline$\geq 65$ years & 598 & $11.6( \pm 15.3)$ \\
\hline \multicolumn{3}{|l|}{ Survival } \\
\hline Overall & 7,274 & $96 \%$ \\
\hline \multicolumn{3}{|l|}{ By sex } \\
\hline Male & 5,017 & $96 \%$ \\
\hline Female & 2,257 & $94 \%$ \\
\hline \multicolumn{3}{|l|}{ By age } \\
\hline 0-18 years & 2,272 & $99 \%$ \\
\hline 19-64 years & 4,444 & $95 \%$ \\
\hline$\geq 65$ years & 422 & $77 \%$ \\
\hline
\end{tabular}

Burns. Author manuscript; available in PMC 2017 January 30. 


\begin{tabular}{lcc}
\hline Patient characteristics $(\mathrm{n}=\mathbf{7 , 6 4 0})$ & $\boldsymbol{n}$ & Mean $( \pm$ SD) or \% \\
\hline ICU stay & \\
\hline Overall mean & $5.1( \pm 20.2)$ \\
\hline Hospital stay & \\
\hline Overall mean & $12.7( \pm 24.7)$ \\
\hline
\end{tabular}

TBSA=total burn surface area 


\section{Table 3}

Bivariate analysis of patient demographics and clinical characteristics

\begin{tabular}{lccc}
\hline \multicolumn{5}{c}{ Live } & Dead & p- Value (p) \\
\hline Age & $30.9( \pm 21.9)$ & $58.3( \pm 20.5)$ & $<0.001$ \\
\hline TBSA & $7.3( \pm 8.7)$ & $39.9( \pm 29.2)$ & $<0.001$ \\
\hline Inhalation & & & $<0.001$ \\
\hline Inhalation injury & $77 \%$ & $23 \%$ & \\
\hline No inhalation injury & $97 \%$ & $3 \%$ & \\
\hline CCI & & & $<0.001$ \\
\hline Mean & $0.8( \pm 1.4)$ & $2.6( \pm 1.9)$ & \\
\hline 0 & $98 \%$ & $2 \%$ & \\
\hline 1+ & $91 \%$ & $9 \%$ & \\
\hline Race & & & \\
\hline White (51\%) & $94 \%$ & $4 \%$ & \\
\hline Other (49\%) & $96 \%$ & $4 \%$ & \\
\hline Sex & & & \\
\hline Male (69\%) & $96 \%$ & $4 \%$ & \\
\hline Female (31\%) & $94 \%$ & $4 \%$ & \\
\hline ICU stay & $4.1( \pm 15.8)$ & $28.6( \pm 47.2)$ & \\
\hline LOS & $11.9( \pm 22.9)$ & $30.6( \pm 47.6)$ & \\
\hline Mechanism & & & \\
\hline Flame (45\%) & $93 \%$ & $7 \%$ & \\
\hline Scald (48\%) & $99 \%$ & $1 \%$ & \\
\hline Other (6\%) & $96 \%$ & $4 \%$ & \\
\hline & & & \\
\hline
\end{tabular}

$\mathrm{TBSA}=$ total body surface area

$\mathrm{CCI}=$ Charlson comorbidity Index

LOS= length of hospital Stay 


\section{Table 4}

Multivariate logistic regression model of mortality in burn cohort

\begin{tabular}{lcc}
\hline Variable & Adjusted odds ratio, 95\% Confidence interval $(C I)$ & $p$-Value \\
\hline TBSA & $1.09(1.08-1.10)$ & $<0.001$ \\
\hline Age & & \\
\hline 0-18 years (reference group) & & \\
\hline 19-64 years & $2.92(1.31-6.52)$ & 0.009 \\
\hline $\mathbf{2 6 5}$ years & $8.34(3.35-20.79)$ & $<0.001$ \\
\hline Inhalation injury & $2.85(1.99-4.08)$ & $<0.001$ \\
\hline Mechanism of injury & & \\
\hline Scald (reference group) & $1.60(1.03-2.50)$ & 0.037 \\
\hline Flame & $2.99(1.57-5.74)$ & 0.001 \\
\hline Other & $1.59(1.441-1.77)$ & $<0.001$ \\
\hline Charlson Comorbidity index $($ CCI $)$ & & \\
\hline
\end{tabular}

TBSA $=$ total body surface area 


\section{Table 5}

Effect of prognostic factors on LA50 \% TBSA $^{a}$

\begin{tabular}{lccc}
\hline & Unadjusted & Partially Adjusted for inhalation injury and mechanism & Fully Adjusted $^{b}$ \\
\hline Overall LA50 \% TBSA & $53 \%$ & $45 \%$ & $35 \%$ \\
\hline Age & & & \\
\hline $\mathbf{1 8}$ years & $81 \%$ & $76 \%$ & $61 \%$ \\
\hline $\mathbf{1 9 - 6 4}$ years & $55 \%$ & $48 \%$ & $43 \%$ \\
\hline $\mathbf{2 6 5}$ years & $30 \%$ & $20 \%$ & $19 \%$ \\
\hline
\end{tabular}

${ }^{a}$ Lethal TBSA burn at which $50 \%$ of the cohort will succumb from the burn injury.

${ }^{b}$ Adjusted for inhalation injury, burn mechanism, and preexisting comorbidities. 